\title{
12 Modeling Small Area Economic Change in Conjunction with a Multiregional CGE Model.
}

Ian Sue Wing

Department of Geography and Center for Energy and Environmental Studies, Boston University, Stone Science Building, 675 Commonwealth Avenue, Boston, MA 02215 isw@bu.edu

William P. Anderson

Department of Geography and Center for Transportation Studies, Boston University, Stone Science Building, 675 Commonwealth Avenue, Boston, MA 02215 bander@bu.edu

\subsection{Introduction}

Regional economic projections are often made at the level of spatial aggregation that is most convenient from political, data and computational perspectives. For example, in the US projections are often made at the level of 50 states. From a policy perspective this makes some sense since disbursements of federal funds for infrastructure are generally made to state governments and sub-state governments have little political representation at the federal level. Economic data is much richer at the state level than at any sub-state level. Also, for many models a larger number of regions than the 50 implies excessive computational burden.

There are, however, a number of economic issues that cannot be adequately addressed at the state level. A few examples include:

Economically depressed regions which seldom coincide with state borders. Even a state as small as New Hampshire has significant differences in economic well being from north to south and large states like Texas may simultaneously contain some of the most affluent and some of the most depressed regions in the country.

Land use change such as the transformation of agricultural land and the general phenomenon of urban sprawl cannot be realistically addressed at the state level.

Environmental pollution studies benefit greatly from spatial disaggregation. It may be possible to estimate aggregate emissions at the state level but not to estimate exposed populations or to provide input to atmospheric models.

In transportation studies, origins and destinations of trips are points rather than areas, so greater spatial detail generates more useful results. Furthermore, the spatial impacts of transportation infrastructure do not necessarily respect state borders.

Our purpose in this paper is to specify a comprehensive and rigorous framework for sub-state economic analysis. In order to do this we must first define a set of substate spatial units. There have been attempts in the past to develop models from economically functional regions rather than political jurisdictions. These include the BEA regions and National Transportation Analysis Regions. From the perspective of data availability it is easier to work with regional definitions that have long histories 
and that are used consistently by different agencies that collect and publish data. In the US this means either counties or Census Metropolitan Areas (CMAs). CMAs are preferable for many types of analysis because they constitute functional regions with high levels of internal spatial interaction. They are not, however, exhaustive (they exclude all rural areas) and only useful for analyzing urban and interurban phenomena. For the model described in this paper we have chosen the 3000 plus US counties as our spatial units. This is an exhaustive regionalization that provides sufficient spatial detail to address some, if not all, of the issues mentioned above. Also, counties can be aggregated up to CMAs and BEA regions.

While a great deal of regional economic analysis has been based on Leontief type Input-Output (IO) models, we have chosen instead to develop a spatially disaggregate Computable General Equilibrium (CGE) model. IO models have the advantages of relatively modest data requirements, a high degree of industrial specificity and a good ability to capture multiplier effects. They are limited, however, to modeling exogenous shocks that can be represented as changes in final demand and they fail to capture supply side effects. As an example of the latter, in the presence of labor supply limitations, large infrastructure investments may result in a combination of increased employment and increased wages. IO models can only capture, and may exaggerate, the employment effect.

How does one develop a CGE model that can make projections at the county level? Is it just a question of applying a state level specification to county level data? The answer is no, for three reasons. First, many types of economic data are not available at the county level. Data for population and employment are available, but data for economic categories like value added and investment are not. Second, models that may be computationally manageable for 50 states may become infeasible for 3000 counties. Finally, there are number issues that become more important for smaller geographical units and must therefore be addressed in a county level model. For example, the issue of available space, which can be neglected at the national or state level, becomes an important constraint on the spatial evolution of activities. Population growth in a county depends not only on its ability to yield utility to new residents but also to the extent to which it is "built out."

The approach we have adopted is to develop a county level model in conjunction with a state level CGE model. Endogenous variables in the state model serve as boundary conditions for the county level. The county level model is not simply an allocation mechanism. It determines a spatial equilibrium distribution of economic activities and population at the county level within each state.

Our emphasis is to develop a model that has a rigorous specification of the supply side - an emphasis that is often lacking in regional models. At this point the demand side of the model is rather aggregate and simple. In later versions of the model, we plan to develop a more comprehensive and explicitly spatial demand side.

The remainder of the chapter is organized as follows. The next two sections describe the state-level and county-level models respectively. While the model is not yet fully operational, we have solved a proof-of-concept model at the state level and conducted empirical estimation of population distribution mechanisms at the state and county levels. These are described in a subsequent section. Finally in the conclusion we speculate about policy analyses that conducted with the model. 


\subsection{A State-Level Computable General Equilibrium Economic Model}

Our first step is to construct a state-level economic simulation model to project the trajectories of output, employment, prices and wages by industry in each of the 50 states over the time horizon 2000-2050 on a series of five-year time-steps. ${ }^{1}$ Our approach is deliberately simple, and, in keeping with the long-run nature of our projections, focuses on the supply side of the economy. We treat the individual industries within each state as representative firms and simulate the dynamics of each according to a Solow-Swan growth model that captures the decision to invest in accumulating a stock of capital in a recursive-dynamic fashion (i.e., based myopically on the values of exogenous and endogenous variables in the current period, rather than looking forward over the entire simulation horizon). ${ }^{2}$ These decisions determine how industry capital stocks in each state evolve from one time-period to the next. Each industry produces output according to a production function that specifies how capital, intermediate goods, and labor-which is assumed to be mobile among states - are combined. In each period, the decisions of the population to migrate among and within states determines the intra-state supply of labor. Industries' competition for workers then simultaneously determines their wages, the prices and quantities of their output, and also the resources available for capital investment in the next period.

\subsubsection{The Within-Period Spatial General Equilibrium Model}

Our first task is to build and calibrate the within-period component of the model, which is a static spatial price equilibrium simulation of the U.S. economy. ${ }^{3}$ In each of the $s$ states in the U.S., assume that there are $j$ industries, each of which produces a single homogeneous commodity indexed by $i$. For each industry in a given state, gross output $(y)$ is produced using capital $(k)$, labor $(l)$ and a composite of intermediate

\footnotetext{
${ }^{1}$ The sectoral disaggregation in Table 1 captures the major sources of air pollutant emissions without being overly detailed. Although simulation modeling is a well established technique for projecting future emissions, there are comparatively few examples of its use to generate longrun forecasts for regions of the U.S. The best example is the REMI economic-demographic model and its antecedents (Stevens and Treyz 1986; Treyz et al 1992; Treyz 1993), which are demand-driven simulations of the spatial economy.

${ }^{2}$ This may be contrasted with an intertemporal optimization framework used in multi-regional climate policy simulations (e.g., Manne and Richels 1992; Nordhaus and Boyer 1999) and dynamic rural-urban computable general equilibrium (CGE) models (e.g., Kelly and Williamson 1984; Becker et al 1992), in which representative agents choose trajectories of investment to maximize their present value of discounted utility from consumption, looking forward over the entire simulation horizons. This approach, although theoretically appealing, is too expensive computationally to work here.

${ }^{3}$ Throughout, we stick to the following notational convention: lower-case letters for industrylevel variables (e.g., prices), upper-case letters for state- and aggregate-level variables (e.g., value added), and tildes ( ) for county-level variables (e.g., housing units). We suppress time subscripts when describing the static equilibrium simulation but include them in our explication of the model's dynamics.
} 
inputs $(x)$, according to a constant-returns-to-scale Cobb-Douglas production function: ${ }^{4}$

$y(j, s)=\xi(j, s) l(j, s)^{\alpha(j, s)} k(j, s)^{\beta(j, s)} x(j, s)^{\gamma(j, s)}$.

Here, $\xi$ is a Hicks-neutral shift parameter, and the parameters $\alpha, \beta$ and $\gamma$ are the value shares of $l, k$ and $m$ in output. $\alpha$ and $\beta$ are derived from the components of value added by state recorded in BEA's Gross State Product (GSP) accounts. $\gamma$ is derived using the coefficients on intermediate input from the latest U.S. social accounting matrix (SAM), constructed from the make and use tables in BEA's Input-Output (I-O) accounts.

We do not observe gross output at the state level-industries' gross state product is synonymous with their value added $(v)$. However, $y$ can be easily inferred from $v$ if we assume that the economy has the same structure of inter-industry demand at both aggregate and the state levels. In the SAM, the coefficient on the use of intermediate input $i$ by industry $j(\bar{X})$ is the average value share of $i$ in $j$ 's gross output. It follows that over all $i$ intermediate inputs:

$p_{X}(j) x(j, s)=\sum_{i} p(i) \bar{X}(i, j) p(j) y(j, s)$,

where $p$ and $p_{X}$ are the price indices of output and the composite of intermediate materials. Constant returns to scale in production implies that:

$p(j) y(j, s)=v(j, s)+p_{X}(j) x(j, s)$,

which enables the value of gross output to be easily imputed as:

$p(j) y(j, s)=v(j, s) /\left(1-\sum_{i} p(i) \bar{X}(i, j)\right)$.

To keep things simple, we propose to model the supply of capital to each industry as being fixed within a period. Competitive equilibrium in output markets results in a zero-profit condition that equates the price of output and the short-run unit cost function that is dual to (12.1):

$p(j)=\left(1+\tau_{Y}(j, s)\right)\left(\psi(j, s) w(j)^{\frac{\alpha}{\alpha+\gamma}} p_{X}(j)^{\frac{\gamma}{\alpha+\gamma}} k(j, s)^{\frac{-\beta}{\alpha+\gamma}} y(j, s)^{\frac{1-\alpha-\gamma}{\alpha+\gamma}}+\bar{R} \frac{k(j, s)}{y(j, s)}\right)$

Here, $p$ is the aggregate price of output in industry $j, \bar{R}$ is the economy-wide average capital rental rate, which we treat as exogenous for simplicity, $w$ is the wage in that industry, $\tau_{Y}$ is the state's tax rate on $j$ 's output in the base year, ${ }^{5}$ and $\psi$ is a Hicks-

\footnotetext{
${ }^{4}$ Scale externalities in production are central to economic models of urbanization and agglomeration (Duranton and Puga 2004). However, including them directly in the production function would result in a non-convex optimization problem which is very difficult to solve (see, e.g, Fan et al 2000). We therefore opt to introduce the effect of external economies parametrically, imposing a neutral decline in the unit cost of production by scaling the value of $\psi$ downward as a concave function of $j$ 's output in state $s$ (i.e., learning-by-doing) or inputoutput based indices of within-state supply or demand linkages (e.g., Bartelsman et al 1994; Paul and Siegel 1999).

${ }^{5}$ For simplicity, we simplify the actual structure of industry taxation, treating taxes as if they were levied on output.
} 
neutral shift parameter whose initial value is calibrated to set the prices of all commodities to unity in the base year. ${ }^{6}$ Simplifying (12.2) to (12.4) enables output in the base year to be calibrated, and permits the quantity and price of intermediate input to be modeled according to a Leontief specification, as follows:

$x(j, s)=\sum_{i} \bar{X}(i, j) y(j, s)$,

and

$p_{X}(j)=\sum_{i} p(i) \bar{X}(i, j) p(j)$.

The initial condition for $w$ is derived from statistics on employment and compensation by industry tabulated in BEA's Annual State Personal Income (ASPI) accounts. The capital rental rate is based on the average value of corporate bond yields. $\tau$ is easily derived from output and tax revenue tabulated in the GSP accounts. It is less straightforward to determine the initial stocks of capital. Following Garofalo and Yamarik (2002), we plan to use the historical data series on aggregate-level investment and depreciation by industry from the BEA's Fixed Assets (FA) accounts, allocate these values among the states in proportion to their shares in value added, and then cumulate the resulting state-level investment and depreciation schedules into stocks of capital using the perpetual inventory method.

We assume that industries face an aggregate demand for their output (YD) that is the sum of own- and other-industry intermediate uses, and final uses by consumers. Intermediate use is determined by the economy's input-output structure and industrial composition. Final use is modeled according to a downward-sloping demand curve that shifts outward with rising aggregate income (GDP):7

$Y_{D}(i)=\sum_{j} \bar{X}(i, j) \sum_{s} y(j, s)+\varpi(i) G D P / p(i)$,

where the parameter $\varpi$ denotes good $i$ 's share of total expenditure on final uses, derived from the SAM. Income balance is achieved by specifying two components to GDP, the sum across states of state-level value added $(V)$ and aggregate tax revenue (TAXREV):

$G D P=\sum_{s} V(s)+T A X R E V$

where

$V(s)=\sum_{j} v(j, s)=\sum_{j}(w(j, s) l(j, s)+\bar{R} k(j, s))$,

and $^{8}$

\footnotetext{
${ }^{6}$ This calibration trick is widely employed in CGE models (Ginsburgh and Keyzer 2000); Dawkins et al 2001).

${ }^{7}$ This formulation models final consumers as an aggregate representative agent with CobbDouglas preferences.

${ }^{8}$ This assumes that tax revenue is recycled as income in a lump sum, a standard practice in CGE modeling.
} 
TAXREV $=\sum_{j} \sum_{s} \tau_{Y}(j, s) P(j) y(j, s)$.

Finally, market clearance for the $i^{\text {th }}$ good implies that aggregate demand equal aggregate supply:

$Y_{D}(j)=\sum_{s} y(j, s)$.

The within-period equilibrium is closed by defining the labor market at the state level. The demand for labor by industry and state is:

$l(j, s)=\frac{\alpha}{\alpha+\gamma} p(j) y(j, s) / w(j)$.

Employment in each state is the sum of the labor demands by that state' industries:

$L(s)=\sum_{j} l(j, s)$.

This expression allows us to specify the average wage at the state level:

$W(s)=\sum_{j} w(j) l(j, s) / L(s)$,

whose value is determined by the distribution of activity levels among industries therein. We propose to employ the simple model of state labor supply developed by Gallin (in press), which models the employment rate $(H)$ in each state as a function of the average wage using a simple labor supply curve:

$H(s)=\chi(s) W(s)^{\eta}$,

where the parameters $\eta$ and $\chi$ denote the average elasticity of labor supply and the base-year employment rate, respectively. The former is usually taken to be around 0.3 in macroeconomic studies, while latter is tabulated in the BLS Local Area Unemployment Statistics. All that is left is to pin down state-level labor supplies, which we model as the product of the employment rate and the population $(N)$, which we assume to be fixed in each period:

$L(s)=H(s) N(s)$.

Equations (12.5) to (12.17) specify the core within-period sub-model. They may be collapsed into a square system of nonlinear simultaneous equations in six unknowns (primal variables $l, x$ and $y$, and corresponding dual variables $w, P X$ and $P$ ) which can be solved for the allocations of labor, intermediate input and output, and the supporting vectors of wages, composite intermediate input prices, and commodity prices that constitute a spatial price equilibrium. ${ }^{9}$

\footnotetext{
${ }^{9}$ It is a straightforward task to specify and solve the model as a mixed complementarity problem (MCP-see Ferris and Pang 1997) in GAMS (Brooke et al 1998) with the MPSGE sub-system (Rutherford 1999). The only potential difficulty is the computational cost of finding a solution to a problem of this size (50 states $\times 20$ industries $\times 6$ equations). The authors will provide an operational proof-of-concept model upon request.
} 


\subsubsection{The Dynamic Process of the Economy}

We now describe the model's dynamic process, which consists of the equations of motion of state-level industry capital stocks and population from one time-step to the next. By specifying the boundary conditions that close the within-period equilibrium problem outlined above, the dynamic problem determines the temporal evolution of the spatial pattern of production.

Our first challenge is to determine the geographic distributions of growth and decline in industries' capital stocks. ${ }^{10}$ We employ a recursive-dynamic approach, which is simple, easily implemented, and allows us to bring to bear on the model's regional forecasts the vast empirical literature on industrial location (e.g., Coughlin et al. 1991; Friedman et al. 1992; Woodward 1992).

Letting the index $t$ denote time periods, we propose to model capital accumulation in each industry within a state using the standard perpetual inventory equation:

$k(j, s, t+1)=\operatorname{inv}(j, s, t)+\kappa(j) k(j, s, t)$,

where inv is the quantity of investment and the parameter $\kappa$ is the average per-period capital survival share in each industry, derived from BEA's Fixed Assets (FA) accounts. As a first cut, we plan to model investment simply as a fixed share (i) of output of the corresponding industry in each state:

$\operatorname{inv}(j, s, t)=\imath(j) y(j, s, t)$.

With (12.19) as a start, our second major task is to develop, numerically calibrate, and test the performance of a more realistic, empirically-based specification for the investment equation. Our preferred approach is the econometrically-calibrated investment accelerator model of Treyz et al. (1992) and Rickman et al. (1993). We propose to adapt this specification to work at the level of individual industries, focusing on two sets of influences on investment:

Those affecting its level-from the macroeconomic literature on capital age structure and turnover (e.g., Caballero et al. 1995; Doms and Dunne 1998; Cooper et al. 1999), and

Those affecting its spatial distribution-from the regional science literature on the effects of state taxes (e.g., Bartik 1985; Holmes 1998), location externalities (e.g., Head et al. 1995). ${ }^{11}$

The second challenge in characterizing the spatio-temporal evolution of economic activity is to specify the determinants of state-level population and labor supply, which depends upon both the growth and migration behavior of the population. Accordingly, we propose to model the evolution of the population in each state as a function of the net growth rate of state populations $(G)$, and economic immigration $(M I)$ and emigration $(M E)$ :

\footnotetext{
${ }^{10}$ These are driven by the industry-state pattern of investment in each period, which is the equilibrium outcome of industries that seek to maximize their returns to capital. Due to the difficulty of computing a solution to the true inter-temporal spatial investment allocation problem, which is highly dimensional, we adopt a simpler approach.

${ }^{11}$ Note that if the technology parameter $\psi$ in the unit cost function (12.5) declines with increasing output, the simple formulation of investment demand in eq. (12.19) will lead to progressive spatial agglomeration.
} 
$N(s, t+1)=N(s, t)(1+G(s, t))+M^{I}(s, t)+M^{E}(s, t)$.

Our third major research task is to estimate the terms on the right-hand side of (12.20). To keep things simple, we avoid explicit characterization of the demographic structure of either state populations or migrants. Instead, we propose to model state population growth using crude birth and death rates by state ( $b$ and $d$, respectively), which are assumed to follow exogenous trends:

$G(s, t)=B(s, t)+D(s, t)=b_{0}(s) e^{b_{1}(s) t}-d_{0}(s) e^{d_{1}(s) t}$.

Here, the parameters $b_{0}, b_{1}, d_{0}$ and $d_{1}$ are estimated on time series data from the National Center for Health Statistics. We also plan to estimate migration flows empirically, in the spirit of Greenwood et al. (1991) and Treyz et al. (1992). We specify gross immigration and emigration at the state level, as well as population redistribution within-state migration $\left(M^{R}\right)$, as functions of states' populations, average population densities $\left(\rho_{N}\right)$, and their wage and employment rates:

$$
M^{\omega}(s, t)=\mu_{0}^{\omega}(s) \rho_{N}(s, t)^{\mu_{1}^{\omega}} N(s, t)^{\mu_{2}^{\omega}} H(s, t)^{\mu_{3}^{\omega}} W(s, t)^{\mu_{4}^{\omega}}, \quad \omega=\{I, E, R\},
$$

in which $\rho_{N}(s, t)=N(s, t) / A(s)$, where $A$ is the land area of state $s$, and $\mu_{0}-\mu_{4}$ are parameters estimated on data from the IRS migration database and BEA's Regional Economic Information System (REIS).

In developing equations for both investment and migration it is natural for tensions to arise between the theoretical correctness of candidate specifications and the consistency of the simulated spatial economy's behavior with our priors when these specifications are included in the model. A key test of the workability of specifications as we implement them is therefore whether the simulated evolution of the geography of production and population is consistent with historical trends (e.g., Kim 1995; Black and Henderson 1999; Holmes and Stevens 2004) or official forecasts (e.g., the Census Bureau's state population projections-Campbell 1996).

\subsubsection{Disaggregating Economic Activity and Population to the County Level}

Our next step is to project the spatial pattern of industry output, population and the demand for transportation at this county scale. This is a process of down-scaling the spatio-temporal evolution of the economic and demographic variables solved for above from the state level to individual counties. We propose to do this via a simple two-step procedure. First, estimating empirical relationships that govern the geographic distribution of output, growth of population and housing stocks, and land use change, and then simulating the resulting set of behavioral equations as a system to solve for the equilibrium spatial distribution of economic activity, population and land use in future periods.

This procedure is the lynchpin of our framework, as it nests fifty county-level spatial allocation problems within the state-level spatial allocation problem outlined above using the solution for the latter problem as the boundary condition for each of the former ones. 


\subsubsection{Spatially Disaggregating Output}

Our first challenge is to distribute output by industry down to the level of individual counties. Employment and compensation are the only variables for which there is comprehensive industry-by-industry coverage at this scale. Accordingly, we begin with labor input. For industry $j$ in state $s$, labor demand $(\tilde{l})$ and total employment $(\tilde{L})$ in each of that state's constituent counties $c\{s\}$ are given by the analogues of equations (12.13) and (12.14):

$\tilde{l}(j, c\{s\})=\frac{\alpha}{\alpha+\gamma} p(j) \tilde{y}(j, c\{s\}) / w(j)$

and

$\tilde{L}(c\{s\})=\sum_{j} \tilde{l}(j, c\{s\})$,

where $\tilde{y}$ denotes $j$ 's level of activity in county $c$. Similarly, the average wage at the county level $(\tilde{W})$ is given by the analogue of equation (12.15):

$\tilde{W}(c\{s\})=\sum_{j} w(j) \tilde{l}(j, c\{s\}) / \tilde{L}(c\{s\})$.

In the base year, $\tilde{l}$ is easily calculated from the Census Bureau's County Business Patterns (CBP) and the ASPI accounts, enabling the initial conditions for $\tilde{y}$ and $\tilde{W}$ to be computed directly from equations (12.23) to (12.25). At subsequent time-steps, $\tilde{y}$ is determined by distributing the equilibrium level of production of industry $j$ in state $s$ found by the state model among counties, enabling (12.23) to (12.25) to be used to calculate $\tilde{l}$ and $\tilde{W}$. Following the Figueiredo et al. (2002) empirical model of manufacturing plant births at the county level, we propose an apportionment procedure that utilizes a logistic sharing rule:

$$
\tilde{y}(j, c\{s\}, t)=y(j, s, t) e^{\tilde{\sigma}(j, c\{s\}, t)} / \sum_{c\{s\}} e^{\tilde{\sigma(j, c \mid c s\}, t)}} .
$$

which represents industry $j$ 's propensity to locate its production in a given county, depends on several county-level variables: average population density $\left(\tilde{\rho}_{N}\right)$, total population $(\tilde{N})$, the average wage, and lagged output (a proxy for local agglomeration externalities):

$\tilde{\sigma}(j, c\{s\}, t)=\sigma\left\langle\tilde{\rho}_{N}(c\{s\}, t), \tilde{N}(c\{s\}, t), \tilde{W}(c\{s\}, t), \tilde{y}(j, c\{s\}, t-1)\right\rangle$.

Our fourth major research task is to specify a functional form for $\sigma$ and econometrically estimate (12.26) and (12.27) using data from the REIS. ${ }^{12}$

\footnotetext{
${ }^{12}$ Recent studies (Henderson 1996; Becker and Henderson 2000; Greenstone 2002) have identified non-attainment of the NAAQS as a large significant influence on industrial location at the county level. While we do not propose to include this feedback in our simulation, we note that it can easily be introduced once a baseline projection of the spatial pattern of emissions is run though an air quality model to give county-level air pollutant concentrations.
} 


\subsubsection{Spatially Distributing Population}

The second challenge is to distribute migration flows calculated in the state model. This enables industrial location in future periods to be simulated by pinning down the level and density of population that affect the right-hand side of (12.27). Census Bureau data give an initial condition for population at the county level $(\tilde{N})$ in the base year. We propose to model the evolution of $\tilde{N}$ in a manner analogous to equation (12.21), where at subsequent time-steps it depends on both population growth (determined by the parent state's birth and death rates in (12.21), and gross immigration $\left(\tilde{M}^{I}\right)$ and emigration $\left(\tilde{M}^{E}\right)$ for that county in the preceding period:

$$
\tilde{N}(c\{s\}, t)=\tilde{N}(c\{s\}, t-1)(1+G(s, t-1))+\tilde{M}^{I}(c\{s\}, t-1)-\tilde{M}^{E}(c\{s\}, t-1) .
$$

County-level migration must sum to the state-level total calculated in (12.22), which is ensured by modeling migration flows according to the logistic sharing rule:

$$
\tilde{M}^{\omega}(c\{s\}, t)=\left(M^{\omega}(s, t)+M^{R}(s, t)\right) e^{\bar{\mu}^{\omega}(c\{s\}, t)} / \sum_{c\{s\}} e^{\bar{\mu}^{\omega}(c\{s\}, t)}, \quad \omega=\{I, E\}
$$

where the propensity to immigrate or emigrate $(\tilde{\mu})$ at the county level mimics equation (12.22):

$\tilde{\mu}^{\omega}(c\{s\}, t)=\tilde{\mu}_{0}^{\omega}(c\{s\}) \tilde{\rho}_{N}(c\{s\}, t)^{\tilde{\mu}_{1}^{\omega}} \tilde{N}(c\{s\}, t)^{\tilde{\mu}_{2}^{\omega}} \tilde{H}(c\{s\}, t)^{\tilde{\mu}_{3}^{\omega}} \tilde{W}(c\{s\}, t)^{\tilde{\mu}_{4}^{\omega}} \tilde{O}(c\{s\}, t)^{\tilde{\mu}_{5}^{\omega}}$.

In this expression, the county employment rate is given by the analogue of (12.17):

$\tilde{L}(c\{s\})=\tilde{H}(c\{s\}) \tilde{N}(c\{s\})$,

$\tilde{\rho}_{N}$ is the population density for a county with land area $\tilde{A}: \tilde{\rho}_{N}(c\{s\}, t)=\tilde{N}(c\{s\}, t) / \tilde{A}(c\{s\})$,

and $\tilde{O}$ is the occupancy rate of housing units $(\tilde{U})$ in $c: \tilde{O}(c\{s\}, t)=\tilde{N}(c\{s\}, t) / \tilde{U}(c\{s\})$. Our fifth major research task is to estimate (12.29) and (12.30) using data from the IRS migration database and the REIS to recover values for the parameters $\tilde{\mu}_{0}-\tilde{\mu}_{5}$.

\subsubsection{The Spatial Pattern of Housing and Land Use}

Our third challenge is to model the process by which growth of population and income generates demand for both new housing and the conversion of land from agricultural to residential, commercial and industrial uses. Specifying this process enables us to simulate future population growth by determining the effect of $\tilde{U}$ on occupancy in (12.30). $\tilde{U}$ is given initially by CBP data for the base year. Over time it responds to the demand-side forces of population, occupancy and income (proxied for by the average wage), and to the supply-side forces of spatial constraints on new builds (proxied for by the average unit density, $\tilde{\rho}_{U}: \tilde{\rho}_{U}(c\{s\}, t)=\tilde{U}(c\{s\}, t) / \tilde{A}(c\{s\})$ ), and 
the availability of land that is "potentially convertible" to residential use ( $\tilde{A}_{P C}$, proxied for by the acreage under agriculture), according to a function $v$ :

$$
\begin{aligned}
& \tilde{U}(c\{s\}, t)=\tilde{U}(c\{s\}, t-1) \\
& \quad+v\left\langle\tilde{\rho}_{U}(c\{s\}, t-1), \tilde{A}_{P C}(c\{s\}, t-1), \tilde{N}(c\{s\}, t-1), \tilde{W}(c\{s\}, t-1), \tilde{O}(c\{s\}, t-1)\right\rangle .
\end{aligned}
$$

Our sixth major research task is to specify and estimate a reduced-form empirical model for $v$.

To simulate future values of $\tilde{U}$ we need to determine $\tilde{A}_{P C}$ in (12.32), which requires us to model land use change. We do this simply by treating each county's total land area as comprising areas that are under residential, industrial and commercial uses $\left(\tilde{A}_{I C R}\right)$, areas that are potentially convertible $\left(\tilde{A}_{P C}\right)$ and areas that are "non-convertible" ( $\tilde{A}_{N C}$, e.g. unusable, wilderness or otherwise protected areas, which we assume to be constant):

$$
\tilde{A}(c\{s\})=\tilde{A}_{I C R}(c\{s\}, t)+\tilde{A}_{P C}(c\{s\}, t)+\tilde{A}_{N C}(c\{s\}) .
$$

Urban sprawl is the progressive conversion of agricultural land to industrial, commercial and residential land at the county level (i.e., growth of $\tilde{A}_{I C R}$ at the expense of $\left.\tilde{A}_{P C}\right)$. The initial conditions for $\tilde{A}_{I C R}$ and $\tilde{A}_{P C}$ are calculated from CBP and Census of Agriculture data. ${ }^{13}$ As in (12.32), $\tilde{A}_{I C R}$ responds to the demand-side forces of population, income and housing unit density, and to availability of potentiallyconvertible land on the supply side, according to a function $\zeta$ :

$$
\begin{aligned}
& \tilde{A}_{I C R}(c\{s\}, t)=\tilde{A}_{I C R}(c\{s\}, t-1) \\
& +\zeta\left\langle\tilde{\rho}_{U}(c\{s\}, t-1), \tilde{N}(c\{s\}, t-1), \tilde{W}(c\{s\}, t-1), \tilde{O}(c\{s\}, t-1), \tilde{A}_{P C}(c\{s\}, t-1)\right\rangle .
\end{aligned}
$$

Our seventh major research task is to specify and estimate a reduced-form empirical model for $\zeta$. This will enable urban growth management policies to be simulated via mandated reductions in $\tilde{A}_{P C}$ that attenuate the growth of $\tilde{A}_{I C R}$. The variables $\tilde{U}$ and $\tilde{O}$ then act as channels through which such policies exert feedback effects on migration and, ultimately, industrial location.

\subsubsection{Spatial Equilibrium at the County Level}

Estimation of equations (12.27), (12.30), (12.32) and (12.34) yields numerical expressions which can be used to simulate the county-level distribution of economic activity, population and land use. The variables that determine the levels of these indicators within each county are for the most part endogenous to the sub-state spatial

\footnotetext{
${ }^{13}$ The Census of Agriculture is the only data source we could find on land use by area at the county level.
} 
pattern of growth. ${ }^{14}$ We must therefore solve the system of equations (12.23) through (12.34) for the equilibrium allocation of industries and population. ${ }^{15}$
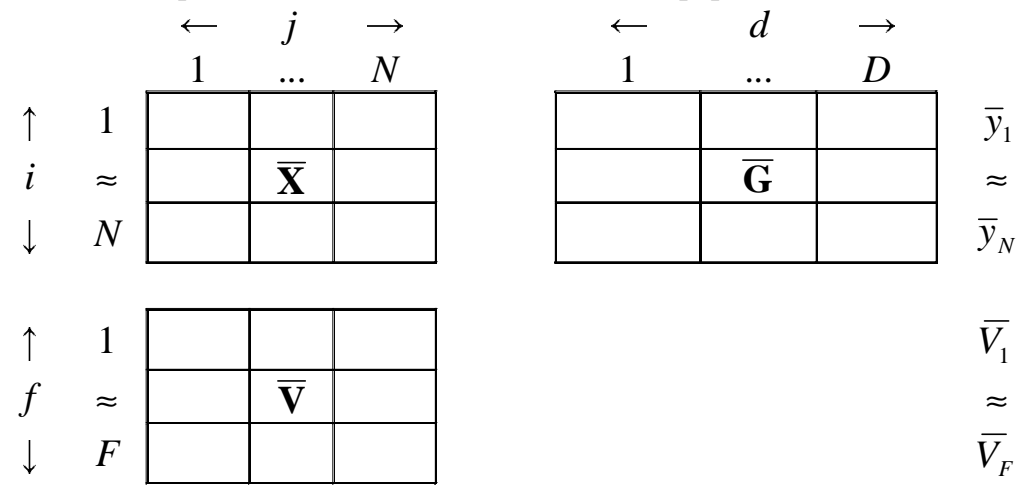

$\approx$

$\bar{V}_{F}$

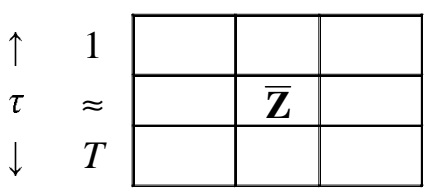

$\bar{y}_{1} \quad \ldots \quad \bar{y}_{N}$

$\overline{G_{1}} \quad \ldots \quad \bar{G}_{D}$

Fig. 12.1 Schematic of the Social Accounting Matrix

\subsection{Preliminary Calibration Efforts}

We calibrate the model on a set of social accounting matrices (SAM) for the U.S. states. The SAM that we use, shown schematically in figure 12.1, comprises an $N \times N$ matrix $\overline{\mathbf{X}}$ of inter-industry transactions, an $F \times N$ matrix $\overline{\mathbf{V}}$ of value-added activities, an $N \times D$ matrix $\overline{\mathbf{G}}$ of final demands, and a $T \times N$ matrix $\overline{\mathbf{Z}}$ of revenue flows due to tax and subsidy distortions. The indices $i, j=\{1, \ldots, N\}$ denote the set of industry sectors, $f=\{1, \ldots, F\}$ denotes the set of primary factors (labor and capital), $d=\{1, \ldots$,

\footnotetext{
${ }^{14}$ In particular, at each future time-step $\tilde{y}$ depends on $\tilde{W}$ by (12.26), but $\tilde{W}$ depends on $\tilde{l}$, and, ultimately, $\tilde{y}$ by (12.23)-(12.25), implying that $\tilde{y}$ is a function of its own level.

Furthermore, $\tilde{y}$ also depends on $\tilde{N}$, which by (12.28)-(12.30) is in turn a function of both its own level in addition to $\tilde{W}$-and therefore $\tilde{y}$, as well.

${ }^{15}$ It is a straightforward task to specify and solve such an equilibrium problem in GAMS as a nonlinear program (NLP) with a dummy objective. The only potential difficulty may be solution problems caused by the global properties of the logistic functions in eqs. (12.26) and (12.29) (Perroni and Rutherford 1998), but this seems unlikely.
} 
$D\}$ denotes the set of final demands (e.g. consumption, investment, government, and net exports), and $\tau=\{1, \ldots, T\}$ denotes the set of distortions.

Official data on state-level SAMs are not published. Traditionally, a SAM must be created for each individual state or region using regional multiplier techniques. However, since our goal is to develop a regional economic model that both explicitly represents state-level detail on the supply side and is consistent with macroeconomic linkages at the aggregate level, we employ a different approach to data development.

The procedure that we use starts by creating a national SAM for the U.S. in the format of figure 12.1, and then disaggregating it into s state-level SAMs. Each of these replicates the structure of the national table (the sub-matrices $\overline{\mathbf{X}}, \overline{\mathbf{V}}, \overline{\mathbf{G}}$ and $\overline{\mathbf{Z}}$ ) through corresponding state-level sub-matrices $\overline{\mathbf{X}}^{s}, \overline{\mathbf{V}}^{s}, \overline{\mathbf{G}}^{s}$ and $\overline{\mathbf{Z}}^{s}$. We use two datasets to perform the disaggregation. The first is 1999 input-output data published by the Bureau of Economic Analysis (BEA), which is used to develop a year 2000 national social accounting matrix (SAM) for the U.S. ${ }^{16}$ The second is year 2000 data on gross state product by industry (GSP) and its constituent components, and annual state personal income (SPI), also from BEA. These data are used to derive each state's share of national value-added and final use according to its fractions of the total across all states of GSP and SPI, respectively.

The components of GSP that are tabulated in the data are labor, property-type income (i.e., a proxy for capital input) and indirect business taxes. Thus, letting the index comp denote these components and GSPC denote their individual contributions to GSP, we have for state s:

$G S P(s)=\sum_{\text {comp }} G S P C(\operatorname{comp}, s)$,

where comp $=\{f, \tau\}$. This notation proves useful in formally describing our disaggregation procedure, to which we now turn.

In keeping with our assumption of a Leontief structure of inter-industry demands, we assume that the relationship between the intermediate inputs to a given industry and its value-added is the one given in the national SAM, and does not depend on state location. Therefore, the values of the column elements of the input-output matrix $\overline{\mathbf{X}}^{S}$ at the state level are determined by the GSP of the corresponding industries, which implies that the national input-output table can be disaggregated according the shares of each state in each industry column:

$\bar{x}^{S}(i, j, s)=\bar{x}(i, j) \frac{G S P(j, s)}{\sum_{s} G S P(j, s)}$.

Although the structure of intermediate demand is fixed, the substitutability of labor for capital implies that the relative intensities of use of these inputs in a given industry

\footnotetext{
${ }^{16}$ The SAM is constructed from the BEA's 92-sector "Make of Commodities by Industries" and "Use of Commodities by Industries" tables for 1999 using the industry technology assumption. Its components of value added are disaggregated using data on industries' shares of labor, capital, taxes and subsidies in GDP published by BEA. The resulting benchmark flow table is aggregated up to three sectoral groupings (primary industries, manufacturing and services), scaled to approximate the U.S. economy in the year 2000 using the growth rate of real GDP from 1999-2000 (3.75 percent), and deflated to year 2000 dollars using the GDP deflator from the NIPAs.
} 
may differ across states, a fact which is borne out by actual data on the components of GSP. The values of elements of $\overline{\mathbf{V}}^{s}$ are thus imputed by separately apportioning among states each individual component of value added in each industry, according to the fraction of each state's contribution to that component of GSP in that industry:

$\bar{v}^{S}(f, j, s)=\bar{v}(f, j) \frac{\operatorname{GSPC}(f, j, s)}{\sum_{s} \operatorname{GSPC}(f, j, s)}$.

Since taxes and subsidies also differ by state, we use the same procedure to impute values for the elements of $\overline{\mathbf{Z}}^{S}$ :

$\bar{z}^{S}(\tau, j, s)=\bar{z}(\tau, j) \frac{\operatorname{GSPC}(\tau, j, s)}{\sum_{s} \operatorname{GSPC}(\tau, j, s)}$.

Finally, we make the simplifying assumption that the structure of state-level final demands reflects the pattern in the national SAM, and that the elements of $\overline{\mathbf{G}}^{S}$ depend not on location but on states' incomes. We therefore used the simple procedure of disaggregating the aggregate final use matrix based on states' shares of total income:

$\bar{g}^{S}(i, d, s)=\bar{g}(i, d) \frac{S P I(s)}{\sum_{s} S P I(s)}$.

The results of this procedure are shown in figure 12.2, which illustrates the disaggregation of a three-sector U.S. national SAM into four SAMs that correspond to the Census regions. It is interesting to note that using the assumptions of (12.39), the row and column totals for each industry do not balance at the state level, but do at the national level. Given that the key assumption of our spatial equilibrium framework is that the law of one price holds for each commodity across all states, the difference between the row and column totals in a state's SAM indicates the magnitude of its net commodity trade flows. This information, along with interstate distances and data from the Department of Transportation's commodity flow survey, may be used to develop detailed state-to-state trade matrices, which can be used to elaborate the simple final demand system in (12.13). (See Appendix, equations A3 and A4.)

With these disaggregate data in hand, it is a simple matter to calibrate the spatial equilibrium model. We use the standard CGE calibration technique of setting all prices to unity and solving for the values of the technical coefficients that replicate the benchmark dataset. ${ }^{17}$ The computational model is formulated and solved using the MPSGE subsystem (Rutherford, 1995, 1999) for GAMS numerical simulation language (Brooke et al., 1999), reproducing the benchmark equilibrium with a residual of $10^{-6}$ (i.e., 10,000 dollars). ${ }^{18}$

\footnotetext{
${ }^{17}$ Sue Wing (in preparation) provides the details. Also see the illustrations of CGE calibration in Mansur and Whalley (1983) and Kehoe (1988). Dawkins et al (2001) provides an comprehensive comparison of different approaches.

${ }^{18}$ The software automatically calibrates the technical coefficients of the excess demand functions, formulates the general equilibrium problem as square system of nonlinear equations, and solves this system as a mixed complementarity problem using the PATH solver (Dirkse and Ferris, 1995).
} 


\begin{tabular}{|c|c|c|c|}
\hline & & & Northeast \\
\hline & $\mathrm{P}$ & M & S \\
\hline $\mathrm{P}$ & 1.09 & 7.46 & 4.61 \\
\hline M & 6.67 & 29.00 & 15.17 \\
\hline $\mathrm{S}$ & 5.28 & 15.79 & 64.65 \\
\hline $\mathrm{L}$ & 6.52 & 21.22 & 103.19 \\
\hline $\mathrm{K}$ & 4.01 & 11.36 & 58.95 \\
\hline $\mathrm{T}$ & 0.09 & 1.90 & 6.79 \\
\hline & 23.66 & 86.73 & $\begin{array}{c}253.37 \\
\text { Midwest }\end{array}$ \\
\hline & $\mathrm{P}$ & $\mathrm{M}$ & $\mathrm{S}$ \\
\hline $\mathrm{P}$ & 2.09 & 8.86 & 4.11 \\
\hline M & 8.98 & 47.00 & 13.65 \\
\hline $\mathrm{S}$ & 7.28 & 24.04 & 58.21 \\
\hline $\mathrm{L}$ & 8.87 & 33.10 & 93.65 \\
\hline K & 5.88 & 16.90 & 49.38 \\
\hline $\mathrm{T}$ & -0.20 & 2.12 & 6.56 \\
\hline & 32.90 & 132.03 & 225.56 \\
\hline
\end{tabular}

\begin{tabular}{|r|}
\hline \multicolumn{1}{|c|}{$U$} \\
\hline 19.14 \\
\hline 43.00 \\
\hline 154.80 \\
\hline \\
\hline \\
\hline 16.93 \\
\hline 43.57 \\
\hline 156.85 \\
\hline
\end{tabular}

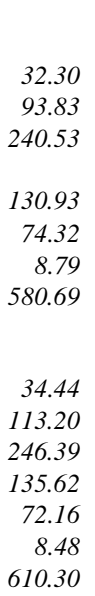

\begin{tabular}{r|r|r|r|}
\multicolumn{1}{c}{} & \multicolumn{2}{c}{ South } \\
\multicolumn{1}{c}{$\mathrm{P}$} & \multicolumn{1}{c}{$\mathrm{M}$} & \multicolumn{1}{c}{$\mathrm{S}$} \\
\cline { 2 - 4 } $\mathrm{P}$ & 5.69 & 14.70 & 6.56 \\
$\mathrm{M}$ & 14.95 & 47.35 & 21.92 \\
\cline { 2 - 4 } $\mathrm{S}$ & 14.59 & 26.00 & 93.03 \\
\cline { 2 - 4 } & & &
\end{tabular}

\begin{tabular}{|r|}
\hline \multicolumn{1}{|c|}{$U$} \\
\hline 28.24 \\
\hline 63.44 \\
\hline 228.42 \\
\hline
\end{tabular}

55.19

\subsection{7}

\begin{tabular}{|l|r|r|}
\hline 13.59 & 30.42 & 148.15 \\
\hline
\end{tabular}

362.05

\section{U.S. National SAM}

\begin{tabular}{|c|c|c|c|c|c|}
\hline & $\mathrm{P}$ & M & $\mathrm{S}$ & $\mathrm{U}$ & \\
\hline $\mathrm{P}$ & 12.53 & 38.96 & 20.09 & 86.68 & 158.26 \\
\hline M & 41.33 & 157.74 & 66.78 & 194.71 & 460.57 \\
\hline $\mathrm{S}$ & \begin{tabular}{|l|}
36.63 \\
\end{tabular} & 83.15 & 284.10 & 701.03 & 1104.90 \\
\hline $\mathrm{L}$ & 39.39 & 106.85 & 449.97 & & 596.21 \\
\hline $\mathrm{K}$ & 27.77 & 63.99 & 253.10 & & 344.85 \\
\hline $\mathrm{T}$ & \begin{tabular}{l|l|}
0.60 \\
\end{tabular} & 9.89 & 30.87 & & 41.36 \\
\hline & 158.26 & 460.57 & 1104.90 & 982.42 & 2706.15 \\
\hline
\end{tabular}

Key:

$\begin{array}{llll}\text { Key: } & \text { Primary industries } & \text { L } & \text { Labor input } \\ \text { P } & \text { Manufacturing industries } & \text { K } & \text { Capital input } \\ \text { M } & \text { Service industries } & \text { T } & \text { Net tax revenue } \\ \text { S } & \text { Final uses } & & \\ \text { U } & \text { P }\end{array}$

Row and column totals in italics All table entries in $\$ 10$ billion 2000 U.S.

Fig. 12.2 Year 2000 Aggregate Social Accounting Matrices for U.S. Census Regions

\subsection{Population Dynamics}

Equations of population movement (12.30), which are used to update the state population from one time step to the next, must be estimated econometrically using Census data on migration and data on socioeconomic characteristics that are endogenous to or can be calculated based on variables that are endogenous to, the within period equilibrium model. Equations (40a-c) were estimated for population movements over the 1995-2000 interval. (All variables as defined in table 12.1). Since decisions to move into, out of, or from one location to another within a particular state are all governed by the same set of forces, we employ seemingly unrelated regression 
specification for the state-level migration equations, which are estimated using threestage least squares:

$$
\begin{aligned}
\text { inm } & =\alpha_{1}+\beta_{1} \text { pop }+\gamma_{1} \text { unemp }+\delta_{1} \text { wage }+\phi_{1} \text { popden }+\theta_{1} \text { occu }+\lambda_{1} \text { unitden } \\
\text { outm } & =\alpha_{2}+\beta_{2} \text { pop }+\gamma_{2} \text { unemp }+\delta_{2} \text { wage }+\phi_{2} \text { popden }+\theta_{2} \text { occu }+\lambda_{2} \text { unitden } \\
\text { intm } & =\alpha_{3}+\beta_{3} \text { pop }+\gamma_{3} \text { unemp }+\delta_{3} \text { wage }+\phi_{3} \text { popden }+\theta_{3} \text { occu }+\lambda_{3} \text { unitden }
\end{aligned}
$$

\begin{tabular}{|c|c|c|c|}
\hline Variable & Description & UNITs & Source \\
\hline inm & $\begin{array}{l}\text { State in-migration, } \\
1995-2000\end{array}$ & 1000 persons & Census Bureau data files \\
\hline outm & $\begin{array}{l}\text { State out-migration, } \\
1995-2000\end{array}$ & 1000 persons & Census Bureau data files \\
\hline intm & $\begin{array}{l}\text { State internal } \\
\text { migration, 1995- } \\
2000\end{array}$ & 1000 persons & Census Bureau data files \\
\hline pop & $\begin{array}{l}\text { State population, } \\
1995\end{array}$ & 1000 persons & BEA State Economic Profiles \\
\hline unemp & $\begin{array}{l}\text { State average } \\
\text { unemployment rate, } \\
1995\end{array}$ & Percent & $\begin{array}{l}\text { BLS Local Area } \\
\text { Unemployment Statistics }\end{array}$ \\
\hline wage & $\begin{array}{l}\text { Av. wage per job, } \\
1995\end{array}$ & current dollars & BEA State Economic Profiles \\
\hline popden & $\begin{array}{l}\text { State population } \\
\text { density, } 1995\end{array}$ & 1000 persons per sq. mi. & $\begin{array}{l}\text { BEA REIS and Census } \\
\text { Gazetteer data files }\end{array}$ \\
\hline unitden & $\begin{array}{l}\text { State av. density of } \\
\text { housing units, } 1995\end{array}$ & Units per sq. mi. & Census Gazetteer data files \\
\hline осси & $\begin{array}{l}\text { State av. occupancy } \\
\text { rates of housing } \\
\text { units, } 1995\end{array}$ & Persons per unit & $\begin{array}{l}\text { BEA REIS and Census } \\
\text { Gazetteer data files }\end{array}$ \\
\hline
\end{tabular}

Table 12.1 List of Variables and Sources

The results are shown in table 12.2. Since popden $=$ occu $\times$ unitden, two variants of equation (12.28) are estimated, one with popden (specification I) and the other with occu and unitden (specification II). Specifications (III) and (IV) in the table control for the influence of population size in the dependent variables, which express the numbers of in- out- and internal migration for each state as fractions of the respective state populations. We attempt to capture the effects of spatial autocorrelation by including spatial lags of the covariates. For each state, the spatial lag of a variable is computed as the average of the values of that variable over all contiguous states. In this calculation $\mathrm{AK}$ and $\mathrm{WA}$, and $\mathrm{CA}$ and $\mathrm{HI}$ are treated as contiguous. These results are shown in table 12.3.

The fit of the regressions is generally good, and is improved by the addition of the spatial lags of the explanatory variables. The size of a state's population is the strongest predictor of all three types of migration, with positive effects on absolute levels of migration and the rate of internal migration, and negative effects on the rates of in- and out-migration.

The effect of average population density-or, equivalently, the combination of unit density and occupancy rates - is negative and significant throughout. While the effects on in-migration and internal migration are of the expected sign (reflecting the congestion costs incurred by migrants in obtaining new lodging), the impact on out- 
migration defies simple explanation. One might be tempted to conclude that high population density may be picking up the influence of access to urban amenities, whose attractiveness attenuates individuals' propensity to move out-of-state, but specification II shows that occupancy rates exert a much stronger negative influence. ${ }^{19}$ This result, which means that the rate of out-migration is declining in the average number of persons per unit, is suggestive of a "life-cycle" effect, whereby small households, comprising singles or couples without children, have a higher propensity to make out-of-state moves. Controlling for spatial autocorrelation, popden's effect on out-migration becomes insignificant, but the negative direct effects of occupancy and unit density remain. The weaker negative effect of lagged population density (and, in specification II, unit density) is consistent with the attenuating influence of congestion costs in neighboring states' housing markets to emigration there.

We find that unemployment has a negative and significant influence on internal migration, but an insignificant effect on in- or out-migration. It is well known that unemployment exerts two countervailing influences on migration-on one hand it reduces households' labor income, and with it the resources necessary to undertake the pecuniary costs of relocation, while on the other hand it acts as a psychic "push" factor, simultaneously inhibiting in-migration and inducing residents to emigrate in search of employment. The results indicate that the former pecuniary effect seems to be the dominant factor. The spatial lag of unemployment has positive and significant effects on both immigration and, to a lesser degree, emigration. The former reflects the influence of relative economic conditions in neighboring states on the propensity of residents of other states to undertake cross-border moves, while the second indicates a regional phenomenon, namely economically-induced migration away from groups of contiguous states which are economically depressed. The estimates of the effect of the average wage, while generally not significant, tend to corroborate this story: they have a positive and significant impact on the propensity to move out-of-state, which presumably involves larger expenditures than internal migration. ${ }^{20}$

Table 12.2 Seemingly Unrelated Regressions for State-Level In-, Out- and Internal Migration

\begin{tabular}{|c|c|c|c|c|c|c|c|c|c|c|c|c|}
\hline & (I) & & & (II) & & & (III) & & & (IV) & & \\
\hline & inm & outm & intm & inm & outm & intm & inmfrac & outmfrac & intmfrac & inmfrac & outmfrac & $\overline{\text { intmfra }}$ \\
\hline \multirow[t]{2}{*}{ pop } & 0.834 & 0.806 & 1.330 & 0.826 & 0.803 & 1.331 & -0.166 & -0.194 & 0.330 & -0.174 & -0.197 & 0.331 \\
\hline & $(0.055)^{* * * *}$ & $(0.027)^{* * * *}$ & $(0.048)^{* * * *}$ & $(0.053)^{* * * *}$ & $(0.027)^{* * *}$ & $(0.048)^{* * * *}$ & $(0.055)^{* * * *}$ & $(0.027)^{* * * *}$ & $(0.048)^{* * *}$ & $(0.053)^{* * *}$ & $(0.027)^{* * * *}$ & $(0.048)$ \\
\hline unemp & $\begin{array}{l}-0.086 \\
(0.198)\end{array}$ & $\begin{array}{l}0.007 \\
(0.099)\end{array}$ & $\begin{array}{l}-0.404 \\
(0.174)^{* *}\end{array}$ & $\begin{array}{l}-0.128 \\
(0.194)\end{array}$ & $\begin{array}{l}-0.010 \\
(0.098)\end{array}$ & $\begin{array}{l}-0.398 \\
(0.176)^{* *}\end{array}$ & $\begin{array}{l}-0.086 \\
(0.198)\end{array}$ & $\begin{array}{l}0.007 \\
(0.099)\end{array}$ & $\begin{array}{l}-0.404 \\
(0.174)^{* *}\end{array}$ & $\begin{array}{l}-0.128 \\
(0.194)\end{array}$ & $\begin{array}{l}-0.010 \\
(0.098)\end{array}$ & $\begin{array}{l}-0.398 \\
(0.176)\end{array}$ \\
\hline wage & $\begin{array}{l}0.327 \\
(0.402)\end{array}$ & $\begin{array}{l}1.022 \\
(0.201)^{* * * *}\end{array}$ & $\begin{array}{l}-0.851 \\
(0.354)^{* *}\end{array}$ & $\begin{array}{l}0.257 \\
(0.393)\end{array}$ & $\begin{array}{l}0.994 \\
(0.198) * * *\end{array}$ & $\begin{array}{l}-0.840 \\
(0.355)^{* *}\end{array}$ & $\begin{array}{l}0.327 \\
(0.402)\end{array}$ & $\begin{array}{l}1.022 \\
(0.201)^{* * * *}\end{array}$ & $\begin{array}{l}-0.851 \\
(0.354)^{* *}\end{array}$ & $\begin{array}{l}0.257 \\
(0.393)\end{array}$ & $\begin{array}{l}0.994 \\
(0.198) * * *\end{array}$ & $\begin{array}{l}-0.840 \\
(0.355)\end{array}$ \\
\hline popden & $\begin{array}{l}-0.089 \\
(0.041)^{* *}\end{array}$ & $\begin{array}{l}-0.096 \\
(0.020)^{* * *}\end{array}$ & $\begin{array}{l}-0.135 \\
(0.036)^{* * *}\end{array}$ & & & & $\begin{array}{l}-0.089 \\
(0.041)^{* *}\end{array}$ & $\begin{array}{l}-0.096 \\
(0.020) * * *\end{array}$ & $\begin{array}{l}-0.135 \\
(0.036)^{* * *}\end{array}$ & & & \\
\hline осcu & & & & $\begin{array}{l}-0.166 \\
(0.060)^{* * *}\end{array}$ & $\begin{array}{l}-0.127 \\
(0.030)^{* * *}\end{array}$ & $\begin{array}{l}-0.123 \\
(0.054)^{* *}\end{array}$ & & & & $\begin{array}{l}-0.166 \\
(0.060)^{* * *}\end{array}$ & $\begin{array}{l}-0.127 \\
(0.030)^{* * *}\end{array}$ & $\begin{array}{l}-0.123 \\
(0.054)\end{array}$ \\
\hline unitden & & & & $\begin{array}{l}-0.073 \\
(0.041)^{*}\end{array}$ & $\begin{array}{l}-0.090 \\
(0.020)^{* * *}\end{array}$ & $\begin{array}{l}-0.137 \\
(0.037)^{* * *}\end{array}$ & & & & $\begin{array}{l}-0.073 \\
(0.041)^{*}\end{array}$ & $\begin{array}{l}-0.090 \\
(0.020)^{* * *}\end{array}$ & $\begin{array}{l}-0.137 \\
(0.037)\end{array}$ \\
\hline
\end{tabular}

\footnotetext{
${ }^{19}$ However, the effect of occupancy rates on out-migration is weaker than on both in-migration and internal migration, and the effect of unit density on out-migration understates that on internal migration, as one might expect based on intuition.

${ }^{20}$ Absent controls for spatial autocorrelation, wages have a counterintuitively strong negative impact on internal migration, but this effect disappears with the inclusion of the spatial lag.
} 


\begin{tabular}{|c|c|c|c|c|c|c|c|c|c|c|c|c|}
\hline Constan & $\begin{array}{c}-1.937 \\
(1.297)\end{array}$ & $\begin{array}{l}-4.146 \\
(0.647)^{* * *}\end{array}$ & $\begin{array}{l}-1.761 \\
(1.140)\end{array}$ & $\begin{array}{l}-1.491 \\
(1.287)\end{array}$ & $\begin{array}{l}-3.968 \\
(0.649)^{* * *}\end{array}$ & $\begin{array}{l}-1.827 \\
(1.163)\end{array}$ & $\begin{array}{l}-1.937 \\
(1.297)\end{array}$ & $\begin{array}{l}-4.146 \\
(0.647)^{* * *}\end{array}$ & $\begin{array}{l}-1.761 \\
(1.140)\end{array}$ & $\begin{array}{l}-1.491 \\
(1.287)\end{array}$ & $\begin{array}{l}-3.968 \\
(0.649)^{* * *}\end{array}$ & $\begin{array}{l}-1.827 \\
(1.163)\end{array}$ \\
\hline Obs. & 50 & 50 & 50 & 50 & 50 & 50 & 50 & 50 & 50 & 50 & 50 & 50 \\
\hline R-sq. & 0.87 & 0.97 & 0.95 & 0.88 & 0.97 & 0.95 & 0.40 & 0.73 & 0.53 & 0.43 & 0.74 & 0.54 \\
\hline
\end{tabular}

All variables in logarithms. Standard errors in parentheses, $*$ significant at $10 \%$; ** significant at $5 \%$; *** significant at $1 \%$

[This table will be re-oriented to fit on the page]

Table 12.3 SUR Results for State-Level In-, Out- and Internal Migration: Effect of Spatial Lags

\begin{tabular}{|c|c|c|c|c|c|c|c|c|c|c|c|c|}
\hline & (I) & & & (II) & & & (III) & & & (IV) & & \\
\hline & Inm & outm & intm & inm & outm & intm & inmfrac & outmfrac & intmfrac & inmfrac & outmfrac & intr \\
\hline \multirow[t]{2}{*}{ pop } & 0.779 & 0.773 & 1.309 & 0.779 & 0.780 & 1.288 & -0.221 & -0.227 & 0.309 & -0.221 & -0.220 & $0.2 i$ \\
\hline & $(0.068)^{* * * *}$ & $(0.031)^{* * *}$ & $(0.061)^{* * * *}$ & $(0.067)^{* * *}$ & $(0.032)^{* * * *}$ & $(0.060)^{* * *}$ & $(0.068)^{* * *}$ & $(0.031)^{* * *}$ & $(0.061)^{* * * *}$ & $(0.067)^{* * * *}$ & $(0.032)^{* * *}$ & $(0 . \mathrm{C}$ \\
\hline \multirow[t]{2}{*}{ unemp } & -0.296 & -0.104 & -0.300 & -0.321 & -0.111 & -0.293 & -0.296 & -0.104 & -0.300 & -0.321 & -0.111 & -0.2 \\
\hline & $(0.211)$ & (0.097) & (0.187) & (0.209) & $(0.100)$ & $(0.185)$ & $(0.211)$ & (0.097) & 87) & (0.209) & & $(0.1$ \\
\hline \multirow[t]{2}{*}{ wage } & 0.501 & 1.100 & -0.644 & 0.455 & 1.064 & -0.585 & 0.501 & 1.100 & -0.644 & 0.455 & 1.064 & -0.5 \\
\hline & $(0.441)$ & $(0.204)^{* * * *}$ & $(0.393)$ & $(0.437)$ & $(0.209)^{* * * *}$ & $(0.387)$ & $(0.441)$ & $(0.204)^{* * * *}$ & $(0.393)$ & $(0.437)$ & $(0.209)^{* * *}$ & $(0.2$ \\
\hline \multirow[t]{2}{*}{ popden } & -0.012 & -0.039 & -0.136 & & & & -0.012 & -0.039 & -0.136 & & & \\
\hline & $(0.059)$ & $(0.027)$ & $(0.053)^{* * *}$ & & & & $(0.059)$ & $(0.027)$ & $3)^{* * *}$ & & & \\
\hline \multirow[t]{2}{*}{ осcи } & & & & -0.115 & -0.089 & -0.111 & & & & -0.115 & -0 & -0.1 \\
\hline & & & & $(0.064)^{*}$ & $(0.031)^{* * * *}$ & $(0.057)^{*}$ & & & & $64)^{*}$ & 1) $)^{* * *}$ & $(0 . C$ \\
\hline \multirow[t]{2}{*}{ unitden } & & & & -0.029 & -0.058 & -0.105 & & & & -0.029 & -0.058 & -0.1 \\
\hline & & & & $(0.054)$ & $(0.026) * *$ & $(0.048)^{* *}$ & & & & $(0.054)$ & 26) $* *$ & (0.C \\
\hline \multirow[t]{2}{*}{$\operatorname{lag}(p o p)$} & -0.017 & 0.015 & -0.166 & -0.028 & -0.003 & -0.104 & -0.017 & 0.0 & -0.166 & -0.028 & -0.003 & -0.1 \\
\hline & (0. & $(0$ & )** & $(0.102)$ & (0.049) & $(0.090)$ & $(0$. & & 3)** & $(0.102)$ & & (0.C \\
\hline \multirow[t]{2}{*}{ lag(unemp) } & 0.982 & 0.491 & -0.085 & 0.943 & 0.541 & -0.271 & 0.982 & 0.491 & -0.085 & 0.943 & 0.541 & -0.2 \\
\hline & $(0.390)^{* *}$ & $(0.180)^{* * * *}$ & $(0.347)$ & $(0.395$ & $(0.188)^{* * * *}$ & $(0.349)$ & $(0.390)^{* * *}$ & $(0.180)^{* * *}$ & & $(0.395)^{* *}$ & $88)^{* * *}$ & $(0.2$ \\
\hline \multirow[t]{2}{*}{ lag(wage) } & -0.454 & 0.047 & -0.916 & -0.879 & -0.369 & -0.386 & -0.454 & 0.047 & -0.916 & -0.879 & -0.369 & -0.2 \\
\hline & $(0.790)$ & $(0.365)$ & $(0.703)$ & $(0.738)$ & $(0.352)$ & $(0.652)$ & $(0.790)$ & $(0.365)$ & & $(0.738)$ & & $(0 . \epsilon$ \\
\hline \multirow[t]{2}{*}{ lag(popden) } & -0.125 & -0.118 & 0.126 & & & & -0.125 & -0.118 & 0.126 & & & \\
\hline & $(0.085)$ & $(0.039)^{* * *}$ & $(0.075)^{*}$ & & & & $(0.085)$ & $(0.039)^{* * *}$ & $(0.075)^{*}$ & & & \\
\hline \multirow[t]{2}{*}{$\operatorname{lag}($ occu $)$} & & & & -0.532 & -0.120 & -0.599 & & & & -0.532 & -0.120 & -0.5 \\
\hline & & & & & & & & & & & & $(0.5$ \\
\hline \multirow[t]{2}{*}{ lag(unitden) } & & & & -0.036 & -0.048 & 0.038 & & & & -0.036 & -0.048 & 0.0 . \\
\hline & & & & $(0.051)$ & $(0.024)^{* *}$ & $(0.045)$ & & & & $(0.051)$ & $(0.024)^{* *}$ & $(0 . \mathrm{C}$ \\
\hline \multirow[t]{2}{*}{ Constant } & -1.819 & -5.169 & 2.342 & 0.408 & -3.496 & 0.614 & -1.819 & -5.169 & 2.342 & 0.408 & -3.496 & 0.6 \\
\hline & $(2.495)$ & $(1.153)^{* * *}$ & $(2.222)$ & (2.191) & $(1.045)^{* * *}$ & (1.937) & $(2.495)$ & $(1.153)^{* * *}$ & $(2.222)$ & (2.191) & $(1.045)^{3}$ & $(1.5$ \\
\hline Obs. & 50 & 50 & 50 & 50 & 50 & 50 & 50 & 50 & 50 & 50 & 50 & 50 \\
\hline R-sq. & 0.89 & 0.98 & 0.96 & 0.89 & 0.98 & 0.96 & 0.51 & 0.81 & 0.61 & 0.51 & 0.80 & 0.6 \\
\hline
\end{tabular}

All variables in logarithms. Standard errors in parentheses, $*$ significant at $10 \%$; ** significant at 5\%; *** significant at $1 \%$

[This table will be re-oriented to fit on the page]

\subsection{Concluding Remarks}

The signal benefit of this research is the creation of a simple, transparent, theoretically and methodologically rigorous simulation model that is suitable for a potentially broad range of applications. Our approach has a number of advantages in this regard, including the following. First, the Hicks-neutral shift parameter $\psi$ may be specified to decline from its calibrated value in the base period one period to the next according to 
projections of productivity growth by industry, facilitating inquiry into the effect of technological progress within industries on the spatial patterns of economic growth. Secondly, because the distribution of industry tax rates in different states affects the spatial pattern of production, the modeler, by changing $\tau_{Y}$ as a policy variable, can explore the impact of future state tax policy scenarios on output and employment. Thirdly, since the consumption of land in the creation of new housing is explicitly modeled, it will be possible to simulate the effect of policies such as limitations on the conversion of non-urban land on county level population growth and economic growth.

The modeling framework is particularly beneficial for conducting environmental analysis for a number of reasons. Because of the relatively detailed distributions of economic activities it will be possible to apply emissions factors to generate spatial patterns of criteria pollutant emissions. This will be useful in identifying areas of high exposures and as input to atmospheric models for ozone and acid deposition. Further, the model may be extended to produce estimates of transportation activity levels and emissions from mobile sources, as described in the Appendix. In addition, the model, by explicitly representing industries' use of intermediate inputs, sheds light on the potential for macro-level climate change policy to affect both regional growth and the spatial distribution of secondary air pollution benefits from reduced combustion activity. A carbon tax $\left(\tau_{C}\right)$ can be simply represented as the additional term $\tau_{C} \varepsilon_{C}\left(j_{C}\right)$ in the unit cost function of the model's fossil fuel sectors $\left(j_{C}\right)$ differentiated according to the average carbon emission coefficients $\left(\varepsilon_{C}\right)$ on these sectors' outputs. Moreover, the income effects of this tax are easily represented by including the revenue that it generates $\left(\sum_{j_{C}} \tau_{C} \varepsilon_{C}\left(j_{C}\right) Y\left(j_{C}\right)\right)$ as an additional term in equation (12.11). This feedback facilitates investigation of the spatial impacts of double dividend policies use the revenue from $\tau_{C}$ to lower $\tau_{Y}$.

\section{References}

Agyemang-Duah, K., W.P. Anderson and F.L. Hall (1995). "Trip Generation for Shopping Travel." Transportation Research Record 1493, 12-20.

Babiker, M.H., et al (2001). "The MIT Emissions Prediction and Policy Analysis (EPPA) Model: Revisions, Sensitivities, and Comparison of Results," MIT Joint Program on the Science \& Policy of Global Change Report No. 71, Cambridge MA.

Bartelsman, E., R.J. Caballero and R. Lyons (1994). "Customer and Supplier Driven Externalities." American Economic Review 84, 1075-1084.

Bartik, T. (1985). "Business Location Decisions in the United States: Estimates of the Effects of Unionization, Taxes, and Other Characteristics of States." Journal of Business and Economic Statistics 3, 14-22.

Black, D. and J.V. Henderson (1999). "Spatial Evolution of Population and Industry in the United States." American Economic Review 89, 321-327.

Brooke, A., D. Kendrick, A. Meeraus and R. Raman (1998). GAMS: A User's Guide, Washington DC: GAMS Development Corp.

Becker, R. and J.V. Henderson (2000). "Effects of Air Quality Regulations on Polluting Industries." Journal of Political Economy 108, 379-421.

Becker, G., E. Mills and J.G. Williamson (1992). Indian Urbanization and Economic Growth Since 1960. Baltimore, Johns Hopkins Press.

Caballero, R.J., E.M.R.A. Engel and J.C. Haltiwanger (1995). "Plant-level Adjustment and Aggregate Investment Dynamics." Brookings Papers on Economic Activity 2, 1-39. 
Campbell, P.R. (1996). Population Projections for States by Age, Sex, Race, and Hispanic Origin: 1995 to 2025. U.S. Bureau of the Census, Population Division, PPL-47.

Cooper, R., J.C. Haltiwanger, and L. Power (1999). "Machine Replacement and the Business cycle: Lumps and Bumps." American Economic Review 89, 921-46.

Coughlin, C., J. Terza, and V. Arromdee (1991). "State Characteristics and the Location of Foreign Direct Investment Within the United States." Review of Economics and Statistics $73,675-683$.

Dawkins, C., T.N. Srinivasan and J. Whalley (2001). "Calibration." In J.J. Heckman and E. Leamer (eds.), Handbook of Econometrics Vol. 5, Amsterdam: Elsevier Science, pp. 3653 3703.

Doms, M. and T. Dunne (1998). "Capital Adjustment Patterns in Manufacturing Plants." Review of Economic Dynamics 1: 409-29.

Duranton, G. and D. Puga (2004). "Microfoundations of Urban Agglomeration Economies." In J.V. Henderson and J-F Thisse (eds.), Handbook of Urban and Regional Economics Vol. 4, Amsterdam, North Holland.

EPA (2003). Compilation of Air Pollutant Emission Factors, AP-42, $5^{\text {th }}$ ed., Vol. 1.

Fan, W., F. Treyz and G.I. Treyz (2000). "An Evolutionary New Economic Geography Model." Journal of Regional Science 40, 671-695.

Ferris, M.S. and J. S. Pang (1997). "Engineering and Economic Applications of Complementarity Problems.” SIAM Review 39, 669-713.

Figueiredo, O., P. Guimaraes and D.P. Woodward (2002). "Modeling Industrial Location Decisions in U.S. Counties." NIMA Working Paper, 18, Universidade do Minho.

Friedman, J., D. Gerlowski, and J. Silberman (1992). "What Attracts Foreign Multinational Corporations? Evidence from Branch Plant Location in the United States." Journal of Regional Science 32, 403-418.

Gallin, J.H. (in press). "Net Migration and State Labor Market Dynamics." Journal of Labor Economics.

Garofalo, G. and S. Yamarik (2002). "Regional Convergence: Evidence from a New State-byState Capital Stock Series." Review of Economics and Statistics 84, 316-323.

Ginsburgh, V. and M. Keyzer (2002). The Structure of Applied General Equilibrium Models, Cambridge, MA., MIT Press.

Greenstone, M. (2002). "The Impacts of Environmental Regulations on Industrial Activity: Evidence from the 1970 and 1997 Clean Air Act Amendments and the Census of Manufactures." Journal of Political Economy 110, 1175-1219.

Greenwood, M.J., G.L. Hunt, D.S. Rickman; G.I. Treyz (1991). "Migration, Regional Equilibrium, and the Estimation of Compensating Differentials." American Economic Review 81, 1382-1390.

Head, K., J. Ries, and D. Swenson (1995). "Agglomeration Benefits and Location Choice: Evidence from Japanese Manufacturing Investments in the United States." Journal of International Economics 38, 223-247.

Henderson, J.V. (1996). "Effects of Air Quality Regulation." American Economic Review 86, 789-813.

Holmes, T.J. (1998). "The Effects of State Policies on the Location of Industry: Evidence from State Borders." Review of Economics and Statistics 81, 314-325.

Holmes, T.J. and J.J. Stevens (2004). "Spatial Distribution of Economic Activities in North America." In J.V. Henderson and J.-F. Thisse (eds.), Handbook of Urban and Regional Economics Vol. 4, Amsterdam, North Holland, pp. xxxxxx

Kelly, A.C. and J.G. Williamson (1984). What Drives Third World City Growth? A Dynamic General Equilibrium Approach. Princeton, N.J., Princeton University Press.

Kehoe, T.J. (1998). "Social Accounting Matrices and Applied General Equilibrium Models." In I. Begg and S.G.B. Henry (eds.), Applied Economics and Public Policy, Cambridge, Cambridge University Press, pp. 59-87.

Kim, S. (1995). Expansion of Markets and the Geographic Distribution of Economic Activity. The Trends in U.S. regional Manufacturing Structure, 1860-1987, Quarterly Journal of Economics 110: 881-908. 
Mansur, A. and J. Whalley (1983). "Numerical Specification of Applied General Equilibrium Models: Estimation, Calibration and Data." In H. Scarf and J. Shoven (eds.), Applied General Equilibrium Analysis, Cambridge, Cambridge University Press, pp. 69-127.

Paul, C.J. and D. Siegel (1999). "Scale Economies and Industry Agglomeration Externalities: A Dynamic Cost Function Approach.” American Economic Review 89, 272-290.

Perroni, C. and T.F. Rutherford (1998). "A Comparison of the Performance of Flexible Functional Forms for Use in Applied General Equilibrium Analysis." Computational Economics, 11, 245-263.

Rickman, D.S., G. Shao and G.I. Treyz (1993). "Multiregional Stock Adjustment Equations of Residential and Nonresidential Investment in Structures." Journal of Regional Science 33, 207-219.

Rutherford, T.F. (1995). "Extensions of GAMS for Complementarity Problems Arising in Applied Economic Analysis.” Journal of Economic Dynamics and Control 19, 1299-1324.

Rutherford, T.F. (1999). "Applied General Equilibrium Modeling with MPSGE as a GAMS Subsystem: An Overview of the Modeling Framework and Syntax." Computational Economics 14, 1-46.

Stevens, B.H. and G.I. Treyz (1986). "A Multiregional Model Forecast for the United States Through 1995." American Economic Review 76, 304-307.

Sue Wing, Ian (in preparation). "Computable General Equilibrium Models and their Use in Economy-Wide Policy Analysis: Everything You Ever Wanted to Know (But Were Afraid to Ask)." Discussion Paper/availability?

Treyz, G.I., A.F. Friedlaender and B.H. Stevens (1980). "The Employment Sector of a Regional Policy Simulation Model." Review of Economics and Statistics 62, 63-73.

Treyz, G.I., D.S. Rickman, G.L. Hunt and M.J. Greenwood (1993). "The Dynamics of U.S. Internal Migration." Review of Economics and Statistics, 75, 209-214.

Treyz, G.I., D.S. Rickman and G. Shao (1992). "The REMI Economic-Demographic Forecasting and Simulation Model.” International Regional Science Review 14, 221-253.

Treyz, G.I. (1993). Regional Economic Modeling A Systematic Approach to Forecasting and Policy Analysis. Boston, Kluwer.

Woodward, D. (1992). "Locational Determinants of Japanese Manufacturing Start-Ups in the United States." Southern Economic Journal 58, 690-708.

\section{Appendix: Estimating Transportation Activity Levels and Mobile Source Emissions}

\section{Personal Transportation Emissions}

We focus on road transportation, and propose a two-track empirical approach that relates vehicle emissions to VMT and driving behavior, both of which are influenced by congestion. Using cross-section data from the National Household Transportation Survey (NHTS), we first estimate a trip generation model of average annual VMT $(\tilde{T})$ as a function of income and size of urban area, and then employ the ordered logit model of Aygemang-Duah et al (1995) to apportion $\tilde{T}$ among a number of average speed categories $\vartheta$ according to geographic attributes. In county $c$, the probability of 
being in speed class $\vartheta$ thus depends on a function $\pi$ of income, population density and size of urban area (both of which proxy for congestion):

$$
\tilde{\pi}(\vartheta, c\{s\})=1 /\left(1+\exp \left[\pi\left\langle\tilde{\rho}_{N}(c\{s\}), \tilde{N}(c\{s\}), \tilde{W}(c\{s\})\right\rangle-\lambda_{\vartheta}\right]\right),
$$

where $\lambda_{\vartheta}$ is an estimated vector of probability cutoffs. The result is a vector of countylevel speed distributions projected at each time-step as a function of the variables solved for at the county level, which serve as a proxy for driving cycle characteristics that affect emissions per mile. This allows us to use the distribution of emissions per VMT in each velocity category from the emission factors in the MOBILE6 model $\left(\varepsilon_{M}\right)$ to estimate mobile emissions ( $\left.\tilde{e}_{M}\right)$ by pollutant, speed class and county:

$$
\tilde{e}_{M}(z, \vartheta, c\{s\}, t)=\tilde{N}(c\{s\}, t) \tilde{T}(c\{s\}, t) \tilde{\pi}(\vartheta, c\{s\}, t) \varepsilon_{M}(z, \vartheta) .
$$

\section{Interstate Freight Transportation Emissions}

An important advantage of the proposed simulation framework is that the model's demand structure facilitates investigation of the impact of regional growth on interstate freight transportation and associated air pollutant emissions. The state-level counterpart of equation (12.8) gives the demand in each state $\left(y_{D}\right)$ for subset of commodities that are transported, $i_{F}{ }^{21}$

$$
y_{D}\left(i_{F}, s, t\right)=\sum_{j} \bar{X}\left(i_{F}, j\right) y(j, s, t)+\varpi(i)(V(s, t)+T A X R E V / N(s, t)) / P\left(i_{F}, t\right) .
$$

This expression allows us to use a production-constrained gravity model to approximate inter-state flows of goods $f$ from production in state $s$ to uses in state $r$ along transportation mode $q$ :

$$
f\left(i_{F}, s, r, q, t\right)=y\left(i_{F}, s, t\right) y_{D}\left(i_{F}, r, t\right) \Delta(s, r, q)^{-\phi(i . q)} / \sum_{r}\left(y_{D}\left(i_{F}, r, t\right) \Delta(s, r, q)^{-\phi\left(i_{F} \cdot q\right)}\right) .
$$

Here, $\Delta$ is the distance from $s$ to $r$, calculated from the BTS North American Transportation Atlas Database, and $\phi$ is a measure of the friction of distance, which our tenth research task is to estimate using cross-sectional data from the 1997 Commodity Flow Survey. We propose to assign the estimated proportions of freight flows by mode to the appropriate transportation network based on shortest path routes, and to focus once again on road transport emissions, which can be easily estimated by multiplying the number of truck miles assigned to each highway link by average highway emissions factors from MOBILE6. ${ }^{22}$

\footnotetext{
${ }^{21}$ Here we assume a simple lump-sum recycling rule that divides aggregate tax revenue equally among members of the population. More realistic assumptions can be made, although at the cost of increasing the model's complexity.

${ }^{22}$ Additional off-interstate emissions are likely to be significant due to local congestion at origin and designation counties. To estimate them it is necessary to account for demand by county as a proportion of each interstate flow.
} 